\title{
The Telephone.
}

$\mathrm{I}^{\mathrm{N}}$ June last, Sir Oliver Lodge read a paper on the history and development of the telephone to the Institution of Electrical Engineers. ${ }^{1}$ The occasion was the jubilee of the invention of the telephone by Graham Bell. The lecturer remembered Graham Bell speaking to the Physical Society of London in 1877. He was impressed by his clear and precise articulation. Graham Bell had devoted himself to the accurate production of human speech not only by his own lips and larynx but also by instrumental means. It is reported that he once said that it was fortunate that he was not a scientifically trained physicist; for if he had been, he would probably have thought that an articulating machine of a simple character was an impossibility. Talking machines had been invented before, but they were very complicated arrangements for producing vowel sounds. In this respect they were unlike the apparatus devised so successfully in our own day by Sir Richard Paget.

Graham Bell's machine took the sounds emanating from the human voice and sought to reproduce them at a distance by electrical methods. The way in which he found that this could be accomplished was surprisingly simple, and on Mar. 10, 1876, the first telephone worked successfully. Sir Oliver recalls how Kelvin showed two of Bell's early instruments at the British Association meeting in Glasgow, and how enthusiastic he was over the marvellous discovery. In these early days the same instrument could be used as a transmitter or a receiver. All the energy put into the circuit, therefore, came from the voice. Very soon, however, the Edison carbon and the Hughes microphone transmitter were invented, batteries were introduced, and the transmission was greatly improved.

When Clerk Maxwell first heard of the telephone, he pictured it in his mind as some instrument of marvellous ingenuity and constructive skill, as much excelling the siphon recorder as the recorder excelled an electric bell. When it first came over he has described his disappointment at its humble appearance, a disappointment only partly relieved by finding that it was able to talk. In this connexion Sir Richard Paget relates how, when Kelvin was staying with Lord Winchelsea, notice arrived that a talking machine, sent by Graham Bell, was coming. Lord Winchelsea dispatched a farm wagon to the station to collect it.

In 1888, Heaviside emphasised the similarity between Lodge's observations on electric waves in wires and Hertz's discovery of waves in free space. They both measured wave-lengths by reflecting them and converting them into stationary waves. Sparks were first used as detectors, but they were given up in 1890 in favour of the coherer principle, which was independently rediscovered and improved by Branly, who used iron filings and smeared.

${ }^{3}$ "The History and Development of the Telephone," Jour. Inst. of Elect. Enyin., vol. 64, p. 1098.

No. 2989, Vol. 119] metallic filings. This method was used in the earliest radio experiments. The discovery of the rectifying power of crystals and thermionic valves in the early years of the present century enormously improved the power to transmit speech and music, and improvements are still continually being made.

Wired and wireless telephony are constantly tending to approximate to one another. It is well known that by the use of accurate tuning and syntonised circuits it is possible to select from the multitude of disturbances in the ether only those of a given frequency. In practice, each sending station sends out carrier waves of definite wavelengths, the voice modifying slightly the shape of these waves. This principle, so extensively used in broadcasting work, can be used for transmitting many telephone messages simultaneously by the same wire. Graham Bell also attempted to use this system in his harmonic telegraph.

In the transmitter and receiver we make use of Faraday's discovery - now nearly a century oldof the induction of currents by moving magnets. The transmitter may be regarded as a kind of dynamo and the receiver as a kind of motor. The transmission takes place by alternating currents flowing round the circuit. Owing to resistance, much of the electric energy is converted into heat. This leads to attenuation of the signals. The circuit also possesses capacity, and this Kelvin took theoretically into account. Heaviside next completed the practical theory by taking the induct. ance into account, and this led to the discovery of the distortionless circuit. Finally, Pupin persuaded American business men to construct 'loaded cables' and long-distance telephony was born.

Fleming's invention of the valve detector, further improved by Lee de Forest, has put into our hands an automatic relay of surpassing docility. Long - line transmission can be attained by a succession of short lengths of land line connected together by valve relays. The currents from the sending stations can now be sent great distances before they are relayed on with fresh energy. The American Telephone and Telegraph Company has in this way effected admirable speech transmission across the American continent.

In radio communication there is little attenuation and distortion. In free space there would be none. The theory of wave transmission in free space is extremely simple. It is only when matter is present that complications are introduced. It is true that there are many things which still seem mysterious to us, but there seems to be nothing that will ultimately be wholly unintelligible. We have bridged the Atlantic with radio telephony and can look forward to the time when sounds will veritably go out unto all lands and be heard by all who care to listen to them. "The progress of science is based upon faith in the ultimate intelligibility of everything : and so far wisdom has been justified of her children." 